\title{
MR Fingerprinting with chemical exchange (MRF-X) to quantify subvoxel T1 and extracellular volume fraction
}

\author{
Jesse I Hamilton ${ }^{\text {**, Mark A Griswold }}{ }^{1,2}$, Nicole Seiberlich ${ }^{1}$ \\ From 18th Annual SCMR Scientific Sessions \\ Nice, France. 4-7 February 2015
}

\section{Background}

MR Fingerprinting (MRF) [1] offers a novel approach for quantifying extracellular volume (ECV) in a single scan without contrast agent. Whereas conventional parameter mapping assumes chemical exchange occurs much faster than the experiment time scale, usually on the order of T1, MRF measurements are acquired every TR (less than 12ms). This project investigates the feasibility of a new MRF acquisition termed MRF-X, which takes chemical exchange effects into account, to generate voxel-wise maps of ECV and T1.

\section{Methods}

Signal evolutions were simulated using the BlochMcConnell equations for two pools with $\mathrm{T} 1_{\text {extra }}=350 \mathrm{~ms}$, $\mathrm{T} 2_{\text {extra }}=30 \mathrm{~ms}, \mathrm{~T} 1_{\text {intra }}=1400 \mathrm{~ms}$, and $\mathrm{T} 2_{\text {intra }}=120 \mathrm{~ms}$, as suggested in [2]. Four tissues were simulated with ECV values of $25 \%$ and $50 \%$, and moderate $\left(\mathrm{k}=8.3 \mathrm{~s}^{-1}\right.$, as in [3]) or fast $\left(\mathrm{k}=1000 \mathrm{~s}^{-1}\right)$ exchange. A standard inversion recovery spin echo experiment was simulated with $\mathrm{TE}=50 \mathrm{~ms}$, TI ranging from $20-3000 \mathrm{~ms}$, and complete relaxation between measurements, and then used to fit apparent monoexponential $\mathrm{T} 1$ values to mimic native T1 mapping. Additionally, an MRF-X sequence with 500 measurements containing pseudorandom flip angles (0$70 \mathrm{deg})$ and TRs $(9-12 \mathrm{~ms})$ was simulated. A sensitivity analysis was also performed by creating a dictionary with the following parameters: $\mathrm{T} 1_{\text {intra }}$ and $\mathrm{T} 1_{\text {extra }} 100$ $2000 \mathrm{~ms}$, exchange rate $1-10 \mathrm{~s}^{-1}$, and ECV $0-100 \%$ $\left(\mathrm{T} 2_{\text {extra }}=30 \mathrm{~ms}\right.$ and $\mathrm{T} 2_{\text {intra }}=120 \mathrm{~ms}$ were fixed). Noise was added to a randomly selected signal evolution before matching it back to the dictionary. This process was

'Biomedical Engineering, Case Western Reserve University, Cleveland, $\mathrm{OH}$, USA

Full list of author information is available at the end of the article

repeated for 1000 entries and SNR levels of 5-100, and the relative error for each parameter was computed as (estimated-actual)/actual. SNR was defined as the maximum in the signal evolution divided by the noise standard deviation.

\section{Results}

Figure 1A shows monoexponential fits for T1 using a standard spin echo inversion recovery sequence. Although two compartments are present, a single effective $\mathrm{T} 1$ is observed that is different from intracellular or extracellular T1 and varies with exchange rate. Figure $1 B$ shows MRF-X signal evolutions for two-compartment voxels with exchange, as well as single compartment voxels having the effective T1 determined by IR spin echo. The signal evolutions are distinguishable with MRF-X but not with standard T1 mapping. Figure 2 shows that MRF-X displays good sensitivity to ECV, intracellular $\mathrm{T} 1$, and extracellular $\mathrm{T} 1$, with $10 \%$ relative error or less for these parameters above $S N R=20$. MRF$\mathrm{X}$ is somewhat sensitive to exchange rate with errors below $40 \%$ at $\mathrm{SNR}=30$ and $25 \%$ at $\mathrm{SNR}=100$; sequence optimization could potentially improve the accuracy in fitting this parameter.

\section{Conclusions}

MRF-X has the potential to quantify subvoxel relaxation parameters and volume fractions when chemical exchange is present and could be used to map ECV in a single scan without exogenous contrast agent.

\section{Funding}

NIH/NIBIB R00EB011527 and Siemens Medical Solutions. 

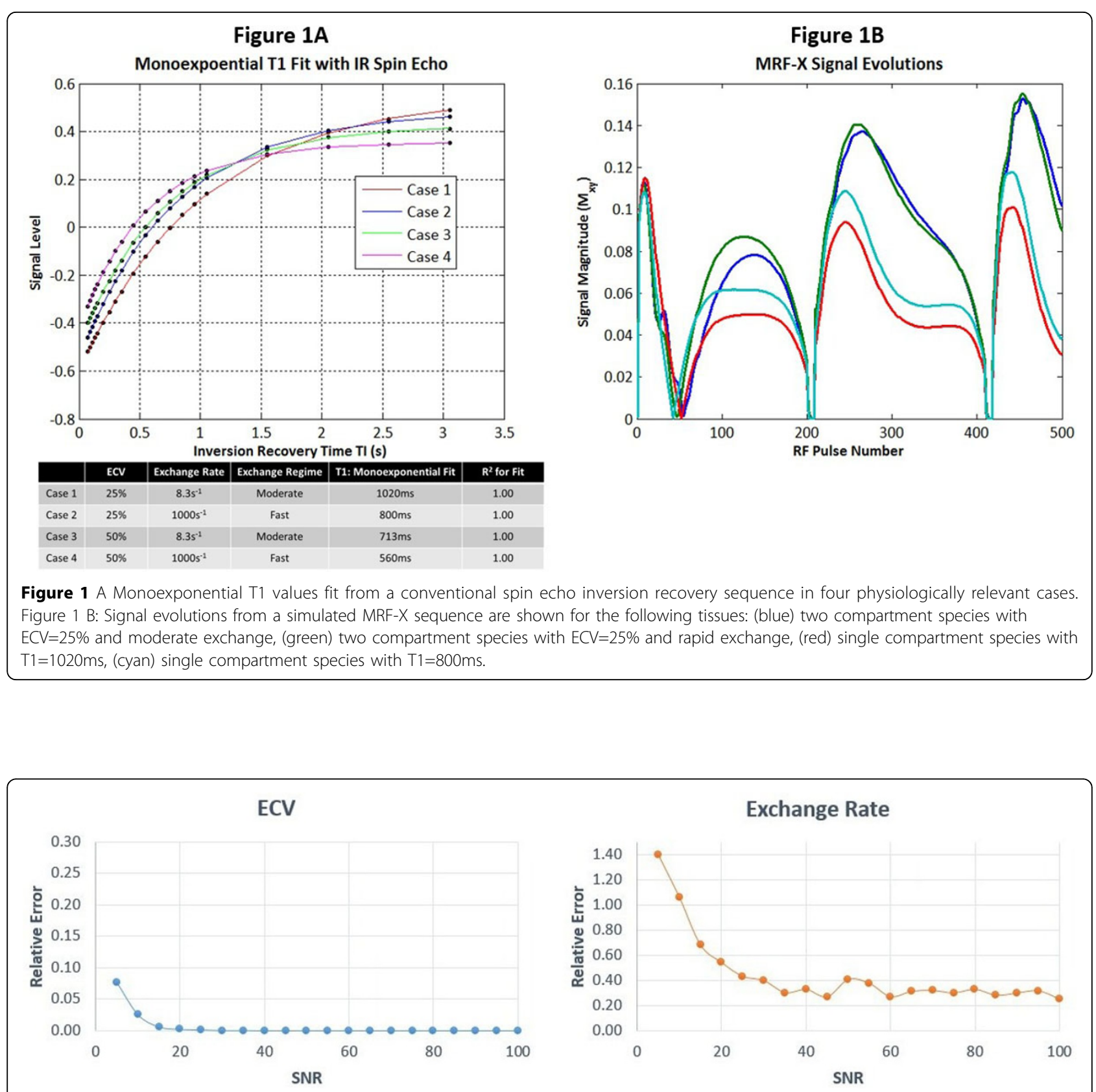

\section{Extracellular T1}

Intracellular T1
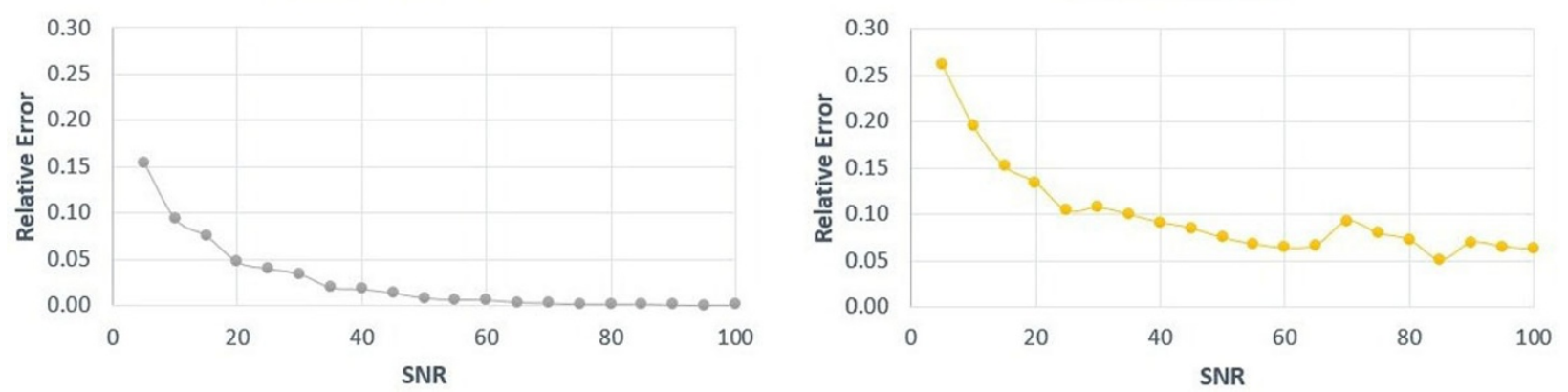

Figure 2 MRF-X sensitivity to ECV, exchange rate, extracellular T1, and intracellular T1 are plotted for different SNR levels. 


\section{Authors' details}

${ }^{1}$ Biomedical Engineering, Case Western Reserve University, Cleveland, $\mathrm{OH}$

USA. ${ }^{2}$ Radiology, Case Western Reserve University, Cleveland, OH, USA.

Published: 3 February 2015

\section{References}

1. Ma, et al: Nature 2013, 495:187-192.

2. Deoni, et al: J Magn Reson Imaging 2008, 27(6):1421-1429.

3. Quirk, et al: Magn Reson Med 50(3):493-499.

doi:10.1186/1532-429X-17-S1-W35

Cite this article as: Hamilton et al:: MR Fingerprinting with chemical exchange (MRF-X) to quantify subvoxel $\mathrm{T} 1$ and extracellular volume fraction. Journal of Cardiovascular Magnetic Resonance 2015 17(Suppl 1): W35.

Submit your next manuscript to BioMed Central and take full advantage of:

- Convenient online submission

- Thorough peer review

- No space constraints or color figure charges

- Immediate publication on acceptance

- Inclusion in PubMed, CAS, Scopus and Google Scholar

- Research which is freely available for redistribution 